\title{
Neuritic Outgrowth Associated with Astroglial Phenotypic Changes Induced by Antisense Glial Fibrillary Acidic Protein (GFAP) mRNA in Injured Neuron-Astrocyte Cocultures
}

\author{
Thierry Lefrançois,, ${ }^{1,2}$ Christiane Fages, ${ }^{1}$ Marc Peschanski, ${ }^{1}$ and Marcienne Tardy ${ }^{1}$ \\ 1/nstitut National de la Santé et de la Recherche Médicale U421, IM3, Faculté de Médecine, 94010 Créteil, France, and \\ Ecole Nationale Vétérinaire d'Alfort, Physiologie Thérapeutique, Laboratoire de Neurobiologie, 94704 Maisons-Alfort, \\ France
}

In the adult CNS, axons fail to regenerate after injury. Among the cell interactions that lead to this failure are those developed with astrocytes. In an effort to elucidate the mechanisms underlying these negative interactions, we have used astrocytes treated with antisense glial fibrillary acidic protein (GFAP) mRNA to inhibit the formation of gliofilaments, indispensable for the astroglial morphological response to injury, and have studied their permissivity for neuritic outgrowth. In a neuronastrocyte coculture, a mechanical lesion led to hypertrophy of astrocytes neighboring the lesion. Neuronal cell bodies and neurites were absent both from the area of lesion and from its surroundings. Reactive astrocytes appeared, therefore, to be a nonpermissive substrate. Transfection that used antisense GFAP mRNA blocked astroglial morphological changes and was characterized by both a persistence of neuronal cell bodies in the vicinity of the lesion site and a growth of neurites into the same region. These morphological differences were associated with a $46 \%$ decrease in the GFAP translation capacity and a $50 \%$ increase in the concentration of GAP-43 in the treated cultures. Neurons were associated mainly with an extracellular laminin network, which was predominant at the lesion site in treated cocultures. In contrast, those astrocytes highly lamininimmunoreactive appeared to be a nonpermissive substrate for neurons. These results show that inhibition in GFAP synthesis, leading to a reduction of astroglial hypertrophy, relieves the blockade of neuritic outgrowth that normally is observed after a lesion. The mechanisms may involve changes in the secretion of extracellular matrix molecules by astrocytes.

Key words: GFAP; antisense mRNA; astrocyte; astroglial hypertrophy; gliosis; regeneration; CNS injury; laminin
Phenotypic changes in astrocytes during maturation or in a state of reactivity may be one factor, among many, that could account for the failure of regeneration of axotomized neurons in the mammalian CNS. It has been well established that, in the injured as well as in the intact developing brain, the growth of axons occurs in the presence of astrocytes that may serve as guides (Schmechel and Rakic, 1979; Silver and Sidman, 1980; Silver et al., 1993). In contrast, regrowth of axotomized axons does not occur in the adult brain, and in this regard the inhibitory role of the astroglial scar has been well documented (for review, see Reier, 1986; Reier and Houle, 1988). Experiments of nitrocellulose filters coated with either embryonic or adult astrocytes (Smith et al., 1986; Rudge and Silver, 1990), in which axonal growth was compared after implantation into a lesioned CNS area, have provided confirmation of this role.

Among the multiple phenotypic changes observed during astroglial maturation, those involved in the functional shift occurring during the maturation time course have been sought actively. It has been shown that astroglial maturation is accompanied by a decrease in molecules such as laminin, NCAM, L1, and heparan sulfate proteoglycan (HSPG) (Ard and Bunge,

Received April 16, 1996; revised March 11, 1997; accepted March 24, 1997.

This work was supported by Institut National de la Santé et de la Recherche Médicale (INSERM) and by Grant PSS0731 from European Community. We thank Jerôme Honorat (INSERM U443, Lyon, France) for the $\mathrm{Hu}$ autoantibody and Elaine Parrish for assistance with English.

Correspondence should be addressed to Dr. Thierry Lefrançois, Institut National de la Santé et de la Recherche Médicale Unité 421, Faculté de Médecine, 8 Rue du Général Sarrail, 94010 Créteil, France.

Copyright (C) 1997 Society for Neuroscience $0270-6474 / 97 / 174121-08 \$ 05.00 / 0$
1988; Smith et al., 1990; McKeon et al., 1995), which are known to promote axonal outgrowth. In favor of a promoting role for those molecules is the fact that the addition of antibodies to L1 and NCAM significantly reduces neurite outgrowth in neuronastrocyte cocultures (Smith et al., 1990). In parallel, the maturation of astrocytes is accompanied by an increase in the synthesis of molecules known to inhibit neurite outgrowth, such as CSPG (chondroitin sulfate proteoglycan) and tenascin (McKeon et al., 1991; Faissner and Steindler, 1995).

One conspicuous phenotypic change occurring in astrocytes during maturation and activation is the major increase seen in the synthesis of intermediate filament proteins, especially the glial fibrillary acidic protein (GFAP) (Eng, 1985; Condorelli et al., 1990; Eng and Ghirnikar, 1994). This major alteration in maturing astrocytes, directly associated with morphological changes, faces us with the possibility of their role in the functional shift from neurite-promoting to neurite-inhibiting elements, something that is still unknown.

The present study has, therefore, been undertaken to determine whether an imposed decrease in GFAP synthesis would affect neurite outgrowth in a neuron-astrocyte coculture under experimental conditions in which astrogliosis has been elicited by a mechanical lesion (Yu et al., 1993). Using antisense GFAP mRNA (Yu et al., 1991), we indeed have observed that phenotypic changes, consecutive to the decrease in GFAP synthesis, induced a functional shift to neurite-promoting elements.

\section{MATERIALS AND METHODS}

In this study astrocyte-neuron cocultures were lesioned mechanically to induce astrocyte reactivity. Morphological observations, immunocyto- 
chemistry, and biochemistry were used to analyze neuronal and glial changes after addition of either antisense GFAP mRNA/lipofectin complex or lipofectin alone.

Neuron-astrocyte coculture and antisense treatment. Highly enriched astroglial primary cultures were obtained from cerebral hemispheres of neonatal Swiss mice (Iffa Credo) by a modification previously described (Andres-Barquin et al., 1994) of the procedure of Mc Carthy and De Vellis (1980). At day 15 the cell population was composed of $\sim 95 \%$ GFAP-positive cells (astrocytes) and 5\% anti-galactocerebroside-positive cells (oligodendrocytes) and anti-Mac1-positive cells (microglia). Neuronal primary cultures were obtained from cerebral hemispheres of $15-\mathrm{d}$ old mouse embryos via the procedure of Hertz et al. (1989). The meninges were removed, and cortical cells were dissociated by trituration in DMEM and filtered through two $80 \mu \mathrm{m}$ filters. The cell suspension was centrifuged $(300 \times g$ for $5 \mathrm{~min})$ and resuspended in DMEM containing $20 \%$ fetal calf serum (FCS). Neurons were seeded onto the astroglial monolayer at a density of $5 \times 10^{5}$ cells $/ \mathrm{ml}$ in the presence of $20 \%$ FCS for $3 \mathrm{hr}$. The medium was removed, and cocultures were incubated with N2 defined medium, i.e., DMEM supplemented with penicillin-streptomycin, $5 \mu \mathrm{g} / \mathrm{ml}$ bovine insulin, $100 \mu \mathrm{g} / \mathrm{ml}$ human transferrin, $20 \mathrm{~nm}$ progesterone, $100 \mu \mathrm{M}$ putrescine, $30 \mathrm{~nm}$ sodium selenite (Sigma, St. Louis, MO), and glucose, as described by Bottenstein (1984). The neurons were allowed to elaborate neurites for $3 \mathrm{~d}$, and then mechanical lesions were performed with the tip of a plastic pipette. In each $35 \mathrm{~mm}$ Petri dish a series of five parallel lesions was performed, followed by a second series, this time perpendicular to the first.

Antisense, lipofectin, and medium were mixed for $10 \mathrm{~min}$. Thirty minutes after the lesion, the cocultures were incubated for $3 \mathrm{hr}$ with or without $8 \mu \mathrm{g}$ of antisense GFAP mRNA, with $16 \mu \mathrm{g}$ of lipofectin (BRL, Bethesda, MD) and $500 \mu \mathrm{l}$ of DMEM and $25 \mathrm{mM}$ HEPES (Life Technologies, Gaithersburg, MD). Then defined medium $(1.5 \mathrm{ml})$ was added. The medium was changed $19 \mathrm{hr}$ after antisense addition. Antisense GFAP mRNA was produced according to $\mathrm{Yu}$ et al. (1991). A $1.25 \mathrm{~kb}$ HindIII restriction fragment was obtained from the $5^{\prime}$ coding end of a 2.5 kb cDNA clone encoding GFAP (generous gift from Dr N. J. Cowan, New York University) and subcloned into PGEM 3z, a SP6/T7 riboprobe vector system (Promega, Madison, WI). The cDNA was linearized by Bam $\mathrm{HI}$ and used as a template in an in vitro run-off transcription reaction (Promega kit). Fifty units of SP6 polymerase were used for $1 \mu \mathrm{g}$ of template. As a control, antisense globin RNA was synthesized in the same manner (the human $\alpha$-globin cDNA was kindly donated by Dr B. Chami, INSERM U91, Créteil, France).

Neurite outgrowth was quantified by image analysis in antisensetreated cocultures and controls $48 \mathrm{hr}$ after lipofection. Both the number of neurites and their maximal length at $5 \mu \mathrm{m}$ of the astrocytic border into the empty area were quantified in 10 randomized areas $150 \mu \mathrm{m}$ wide in diameter (in each condition for five separate experiments).

Immunocytochemical analysis. Two types of protocol were used to identify different immunoreactions. In the first, cells were fixed with $4 \%$ paraformaldehyde $/ 0.2 \%$ picric acid for $1 \mathrm{hr}$ and post-fixed with cold methanol for $3 \mathrm{~min}$. After a $30 \mathrm{~min}$ permeabilization with PBS and $0.1 \%$ Triton X-100, cells were incubated for $1 \mathrm{hr}$ at room temperature and for $24 \mathrm{hr}$ at $4^{\circ} \mathrm{C}$ with the primary antibodies in PBS plus $0.1 \%$ BSA. This protocol was used for the detection of GFAP (rabbit GFAP antiserum 1:25; Dakopatts, Copenhagen, Denmark), $\mathrm{Hu}$ (human $\mathrm{Hu}$ antiserum, 1:50; gift of Dr. J. Honorat, INSERM U443, Lyon, France)-a human autoantibody that stains specifically neuronal perikarya (Marusich and Weston, 1992)-laminin (rabbit laminin antiserum, 1:10; Sigma), and fibronectin (rabbit fibronectin antiserum, 1:50; Biomakor). In the second protocol, used for the detection of GFAP (1:50; Dakopatts), MAP5 (1:10; Boehringer Mannheim, Mannheim, Germany) and GAP-43 (1:10; Boehringer Mannheim) cells were fixed with cold methanol $\left(-20^{\circ} \mathrm{C}\right)$ for $5 \mathrm{~min}$ and incubated for $45 \mathrm{~min}$ at room temperature with the appropriate antibodies in PBS. In both protocols cells subsequently were washed extensively and reincubated with the appropriate secondary antibodies (sheep anti-rabbit antibodies/TRITC, 1:50, Cappel, West Chester, PA; goat anti-human antibodies/FITC, 1:25, Biomakor; sheep anti-mouse antibodies/FITC, 1:50, Boehringer Mannheim) in PBS for $45 \mathrm{~min}$ at room temperature. Finally, dishes were washed thoroughly and cut out. The plates were fixed on slides, coverslipped with Immunomount, and observed through a Nikon fluorescence microscope. All results were controlled for specificity by omitting the primary antibody.

Biochemical analysis. To control the uptake of antisense mRNA in the cells, we synthesized an antisense GFAP mRNA in the presence of ${ }^{33} \mathrm{P}$ CTP $\left(200 \mu \mathrm{Ci}, 37 \times 10^{6} \mathrm{cpm}\right.$ for $1 \mu \mathrm{g}$ of cDNA, Isotopchim $)$. At 3,10 , and $19 \mathrm{hr}$ after treatment with this labeled antisense, cells were washed extensively with HBSS (Seromed, Berlin, Germany) and then collected by scraping in $0.1 \%$ sodium dodecylsulfate. The radioactivity of the cell extract was determined in a liquid scintillation counter (Searle) as a percentage of the total radioactivity added to the culture. For in situ visualization one dish was washed with PBS, brought into contact with an emulsion (LM1; Amersham, Les Ulis, France), and developed $3 \mathrm{~d}$ later. Cells were counterstained with cresyl violet.

For Western blot analysis the medium was removed, and each dish was rinsed three times with HBSS. The cells were collected by scraping into $62.5 \mathrm{~mm}$ Tris $\mathrm{HCl}, \mathrm{pH} 6.8,2 \mathrm{~mm}$ EDTA, $2 \mathrm{~mm}$ phenylmethylsulfonyl fluoride (PMSF), $0.5 \%$ Triton X-100, and $2.3 \%$ sodium dodecyl sulfate. Total protein content was determined by the method of Lowry et al. (1951) with bovine serum albumin as a standard. Total protein (4 $\mu \mathrm{g})$ was boiled for $5 \mathrm{~min}$ after addition of $10 \%$ glycerol $/ 5 \%$ mercaptoethanol. The proteins were analyzed by Western blotting (SDS polyacrylamide gel electrophoresis, followed by electrophoretic transfer of proteins to nitrocellulose sheets) under the conditions described by Laemmli (1970). The sheets were incubated either with polyclonal anti-GFAP (1:100; Dakopatts) or monoclonal anti-GAP-43 or anti-vimentin (1:50; Boehringer Mannheim) and revealed with anti-rabbit or anti-mouse IgG coupled to ${ }^{125} \mathrm{I}$, as previously described (Andres-Barquin et al., 1994).

To analyze specifically the impairment in the neosynthesis of GFAP induced by the application of GFAP antisense mRNA, we used in vitro translation of GFAP mRNA. RNA extraction was performed from six pooled Petri dishes, according to Chomczynsky and Sacchi (1987), with guanidine thiocyanate (4 $\mathrm{m}$ guanidine thiocyanate, $25 \mathrm{~mm}$ sodium citrate, $0.5 \% \mathrm{w} / \mathrm{v}$ sodium $N$-laurylsarcosine, and $0.1 \mathrm{M} \beta$-mercaptoethanol, $\mathrm{pH} 7$ ) in two separate experiments. Cells were homogenized by using an ultra Turax homogenizer for $30 \mathrm{sec}$ at minimal speed and then mixed with 0.1 vol of sodium acetate, $\mathrm{pH} 4,0.5$ vol phenol, and 0.1 vol chloroform/ isoamyl alcohol $(49: 1)$ and centrifuged for $15 \mathrm{~min}$ at $3500 \times \mathrm{g}$ at $4^{\circ} \mathrm{C}$. The supernatants were decanted and mixed with 0.9 vol of isopropyl alcohol and then placed at $-20^{\circ} \mathrm{C}$ for $1 \mathrm{hr}$ to precipitate the nucleic acids, which were collected by centrifugation at $10,000 \times g$ for $30 \mathrm{~min}$ at $4^{\circ} \mathrm{C}$. The pellets were rinsed with $70 \%$ ethanol, dried, and finally dissolved in sterile water. RNA concentrations were evaluated by spectroscopy at $260 \mathrm{~nm}$, and their quality was examined by minigel analysis. Translation was performed at $30^{\circ} \mathrm{C}$ for $90 \mathrm{~min}$ in aliquots of $50 \mu \mathrm{l}$ containing $200 \mu \mathrm{g} / \mathrm{ml}$ RNA, $1 \mu \mathrm{Ci} / \mu \mathrm{l}\left[{ }^{35} \mathrm{~S}\right]$ methionine, $1 \mathrm{~mm}$ amino acid mixture excluding methionine, $700 \mu \mathrm{l} / \mathrm{ml}$ rabbit reticulocyte lysate treated with nuclease (Promega), and $40 \mathrm{U}$ RNAsine (Promega). The incorporation of methionine into total translated proteins was determined by trichloroacetic acid precipitation on a $2 \mu \mathrm{l}$ translation assay sample. GFAP was immunoisolated from the translation mixture containing at least $0.5 \times 10^{6} \mathrm{cpm}$, according to Smith and Campbell (1983). The mixture was diluted to $1 \mathrm{ml}$ with $10 \mathrm{~mm}$ Tris- $\mathrm{HCl}, \mathrm{pH} 7.4$, containing $0.1 \%$ SDS, $0.5 \%$ Triton X-100, $150 \mathrm{~mm} \mathrm{NaCl}, 10 \mathrm{~mm}$ EDTA, and $0.1 \mathrm{~mm}$ PMSF. This solution was precleared with $20 \mu \mathrm{l}$ of $10 \%$ Staphylococcus aureus cells (Life Technologies) and incubated at $4^{\circ} \mathrm{C}$ for $30 \mathrm{~min}$. Cells subsequently were removed by centrifugation.

GFAP antiserum $(5 \mu \mathrm{l})$ was added to the supernatant solution, and the mixture was incubated for $1 \mathrm{hr}$ at room temperature and overnight at $4^{\circ} \mathrm{C}$. Fifty microliters of $10 \%$ Staphylococcus aureus cells were added, and the mixture was incubated at room temperature for $1 \mathrm{hr}$. The cells were washed with the dilution buffer and boiled for $3 \mathrm{~min}$. The proteins were separated by electrophoresis in $10 \%$ SDS-polyacryamide, and the gels were fluorographed, dried, and analyzed.

\section{RESULTS}

The neuron-astrocyte cocultures showed cortical neurons homogeneously distributed over the astrocyte monolayer. Neurons extended many neurites after $3 \mathrm{~d}$ (Fig. 1a). Astrocytes were large and flattened; neuron cell bodies appeared rounder and denser than astrocytes under phase-contrast microscopy. This morphological identification of the cell types was fully confirmed by immunolabeling with GFAP for astrocytes and with $\mathrm{Hu}$ or MAPs for neurons. Mechanical lesions provoked changes in morphology, immunocytochemistry, and biochemistry that differed depending on the presence or the absence of antisense GFAP mRNA. 

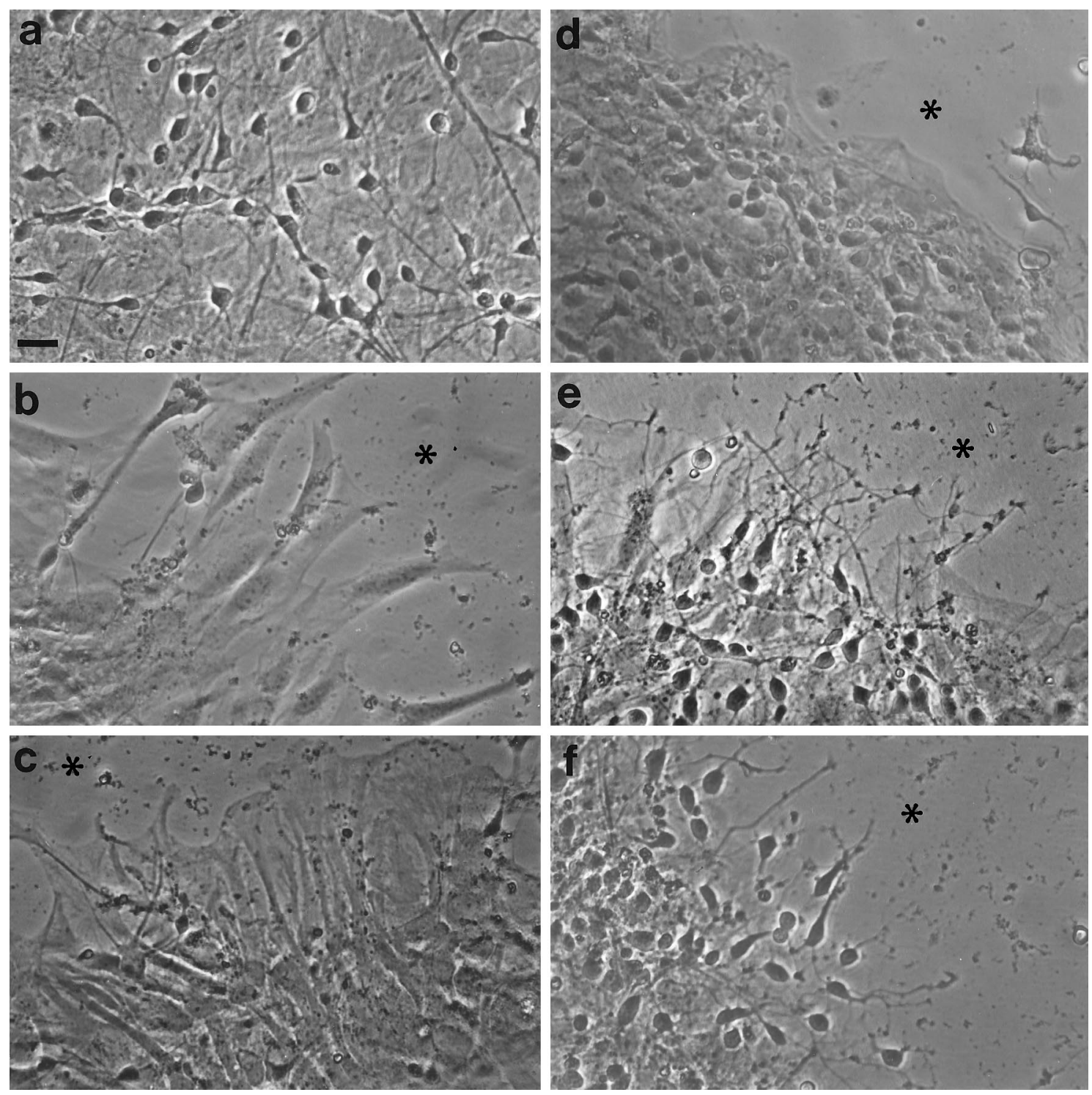

Figure 1. Phase-contrast micrographs of transfected cocultures. $a$, The cocultures before lesion. Lesioned cocultures were treated with $16 \mu \mathrm{g}$ of lipofectin for $24(b)$ or $48 \mathrm{hr}(c)$ or with $16 \mu \mathrm{g}$ of lipofectin associated with $8 \mu \mathrm{g}$ of antisense GFAP mRNA for $24(d), 48(e)$, or $72 \mathrm{hr}(f)$. Asterisks correspond to the initial lesion site. All pictures are recorded at the same magnification. Scale bar, $10 \mu \mathrm{m}$.

\section{Morphological and immunocytochemical analysis of untreated neuron-astrocyte cocultures}

Mechanical lesions were visualized easily as empty lines with no apparent cellular structure. After injury, morphological changes in both astrocytes and overlying neurons were visible at a distance up to $200-400 \mu \mathrm{m}$ around the lesions. No change was observed in remote areas. These changes were progressive over time. At $24 \mathrm{hr}$ after injury the size of astrocytic cell bodies was increased. Astrocytes extended large and thick processes perpendicular to the lesion, some of them entering the acellular area (Fig. 1b). GFAP immunolabeling confirmed the presence of large astrocytes that displayed hypertrophic processes entering the lesion site (Fig. $2 a$ ). Few neurons were seen in the vicinity of the lesion (Figs. $1 b, 2 a$ ). At $48 \mathrm{hr}$ postlesion giant astrocytes began to fill the lesion site (Fig. 1c). Neurons were not observed in the reoccupied zone (Figs. 1c, 2b). Moreover, these few neurons presented few, if any, neurites labeled with the use of MAP5 antibodies (Fig. 2b). In the vicinity of the lesion neuritic staining was also less dense than in remote areas (Fig. 2b).

At all times studied, two different patterns of laminin staining were observed: an astroglial perinuclear immunolabeling, mostly present in large and flat astrocytes of the lesion border, with little, if any, extracellular staining (Fig. 3a); and an immunolabeled network mostly, if not exclusively, extracellular, present all over the coculture, excluding the lesion border (Fig. $3 b$ ). Hu-labeled neurons were observed predominantly in contact with the laminin extracellular network (Fig. $3 b$ ) but not over laminin-immunoreactive astrocytes (Fig. 3a,b). Fibronectin staining was observed merely extracellularly (data not shown); it also was organized into a complex network. Distribution of $\mathrm{Hu}$-labeled neurons was not related specifically to the fibronectin network.

Similar results were observed when lipofectin or lipofectin with antisense $\alpha$-globin mRNA was added to the coculture (data not shown). 

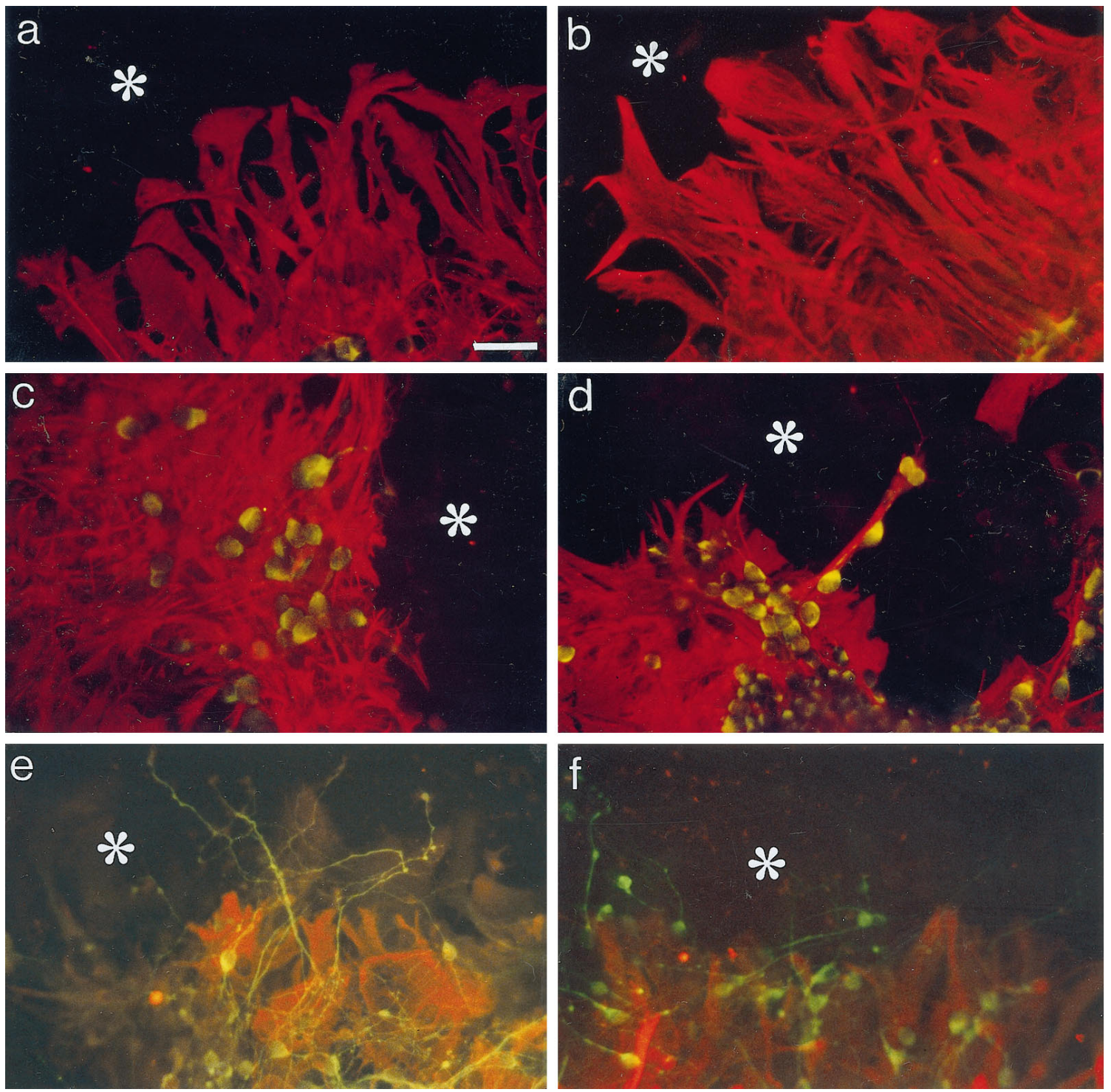

Figure 2. Immunostaining for GFAP (in red) and Hu (in green) or GFAP (in red) and MAP5 (in green) in cocultures. Immunocytochemistry was performed with rabbit GFAP antiserum (1:50), human autoantibody Hu $(1: 100)(a-d)$, and mouse MAP5 antiserum $(1: 10)(e, f)$. Lesioned cocultures were treated with $16 \mu \mathrm{g}$ of lipofectin for $24(a)$ or $48 \mathrm{hr}(b)$ or with $16 \mu \mathrm{g}$ of lipofectin associated with $8 \mu \mathrm{g}$ of antisense GFAP mRNA for $24(c)$, $48(d$, $e)$, or $72 \mathrm{hr}(f)$. Asterisks correspond to the initial lesion site. Pictures are recorded at the same magnification $(400 \times)$. Scale bar, $10 \mu \mathrm{m}$.

\section{Morphological and immunocytochemical analysis of neuron-astrocyte cocultures treated with antisense GFAP MRNA}

After treatment with antisense GFAP mRNA, 30 min after injury, morphological changes around the lesion sites were different from those described above. At $24 \mathrm{hr}$ after injury the border of the acellular zones was straight, and hypertrophic astrocytes with large GFAP-labeled processes were not apparent (Figs. 1d, 2c). Many neuronal cell bodies were observed on the astrocytes bordering the lesion (Figs. 1d, 2c). Hu immunostaining was heavy (Fig. 2c). At $48 \mathrm{hr}$ postlesion some neuronal cell bodies had entered the lesion site accompanying a thin astrocytic process (Fig. $2 d$ ). Phase-contrast microscopy (Fig. 1e), MAP5 immunolabeling (Fig. 2e), and GAP-43 immunolabeling (see Fig. 6) showed neurons extending neurites and growth cones into the lesion site. At $72 \mathrm{hr}$ after injury neuronal cell bodies and neurites had filled the lesion border, as seen with phase-contrast microscopy (Fig. 1f) or with MAP 5 immunolabeling (Fig. $2 f$ ). The number of neurites extending $>5 \mu \mathrm{m}$ away from the astrocytic border into the previously lesioned area was $14.0 \pm 2.0$ (mean \pm SEM) in antisensetreated cultures versus $0.08 \pm 0.05$ in controls, and the maximal length of these neurites was $54.6 \mu \mathrm{m} \pm 4.1$ (mean \pm SEM) versus $0.63 \mu \mathrm{m} \pm 0.39$ in controls.

Laminin-immunostained astrocytes were scarce. In contrast, the network of laminin immunostaining, mostly extracellular, was prominent (Fig. 3c,d). Hu immunoreactive neurons were in contact with this laminin network (Fig. $3 c, d$ ).

\section{Biochemical analysis}

Control of the uptake of antisense GFAP mRNA with the use of radiolabeling revealed the presence of staining in the cytoplasm, close to the nucleus, of approximately one-half of the cell population (Fig. 4). The uptake efficiency of antisense mRNA, defined as the percentage of radiolabeled antisense GFAP mRNA found in the cells as compared with the total radiolabeled antisense added to the culture, was 24 or $26 \% 3 \mathrm{hr}$ after transfection, 21 or 

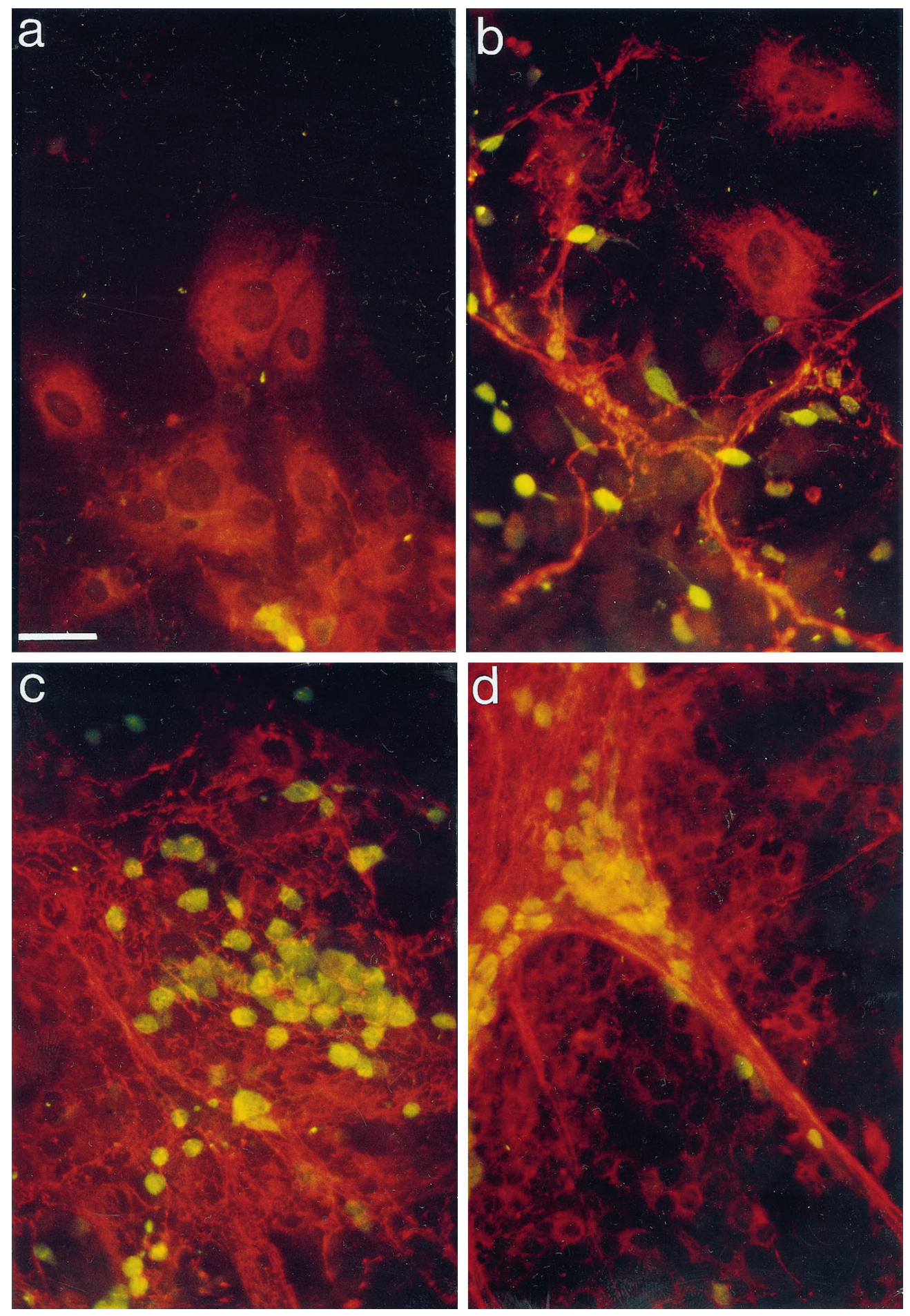

Figure 3. $\mathrm{Hu}$ (in green) and laminin (in red) immunolabeling in injured cocultures. Immunocytochemistry was performed with $\mathrm{Hu}$ antiserum (1:100) and mouse laminin antiserum (1:10). $a$ and $b$ are control cocultures; $c$ and $d$ are antisense-treated cocultures. Laminin immunoreactivity is observed in astrocytes and as an extracellular filamentous network. Scale bar, $10 \mu \mathrm{m}$.

$25 \%$ at $10 \mathrm{hr}$, and 17 or $21 \%$ at $19 \mathrm{hr}$ (results of two separate experiments).

This uptake of antisense GFAP mRNA had biochemical consequences illustrated by a decrease in the translational capacity of the cells for GFAP and a decrease in GFAP synthesis. In vitro translation assays with equivalent amounts of total RNA showed a similar total translation rate in treated and untreated cocultures. Electrophoretic separation of the different translation products revealed a $50 \mathrm{kDa}$ protein corresponding to GFAP. Densitometric evaluation of this 50 $\mathrm{kDa}$ fraction indicated that antisense treatment provoked a decrease in GFAP translation efficiency of 16 or $8 \%$ of the control value $3 \mathrm{hr}$ after transfection and of 53 or $35 \% 19 \mathrm{hr}$ after transfection (results of two separate experiments). Under antisense conditions additional translated GFAP-immunoprecipitated peptides of $\sim 44,41,26$, and $24 \mathrm{kDa}$ were observed (Fig. 5). These additional bands were not observed, however, in parallel Western blots, and Northern blots showed only one GFAP transcript, suggesting that they were attributable to a technical artifact. Western blot analysis showed a significant decrease in GFAP of $20 \pm 3 \%(n=4$, mean \pm SEM $)$ in antisense-treated cocultures, as compared with control at 24 and 36 hr. GFAP levels returned to control values at $3 \mathrm{~d}$.

Vimentin levels were not altered by the antisense treatment. In 


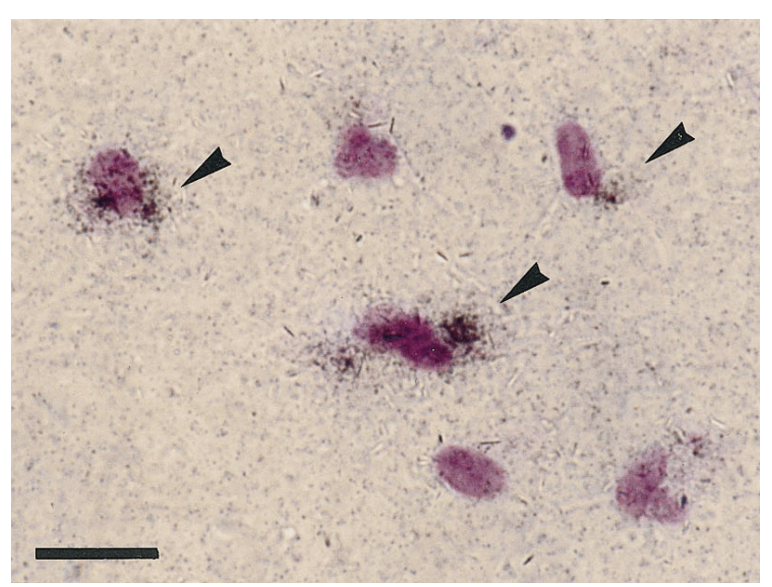

Figure 4. Micrograph of coculture $3 \mathrm{hr}$ after transfection with $16 \mu \mathrm{g}$ of lipofectin and $8 \mu \mathrm{g}$ of radiolabeled antisense GFAP mRNA. Arrows point to clusters of silver grains revealing antisense GFAP mRNA. Cells were counterstained with cresyl violet. Scale bar, $5 \mu \mathrm{m}$.

sharp contrast, GAP-43 increased $36 \mathrm{hr}$ after treatment in three separate experiments, as compared with controls, by a mean of $50 \pm 14 \%$ (mean \pm SEM; range, 31-70\%).

\section{DISCUSSION}

In this paper we have sought to identify the role of phenotypic changes in astrocytes in the failure of axonal regeneration after mechanical lesion. This analysis was based on a specifically designed coculture system that appeared to reproduce adequately in vitro the phenomena characterized in vivo. In this experimental setup addition of an antisense GFAP mRNA was proved efficient in blocking the inhibition of neurite outgrowth into a mechanical lesion. These results support the hypothesis that morphological hypertrophy of astrocytes, associated with GFAP synthesis, is responsible, directly or indirectly, for the inhibitory role of the so-called glial scar on axonal regeneration.

\section{An in vitro model for CNS injury}

To analyze in vitro the interaction between neurons and astrocytes in the vicinity of a mechanical lesion, we have designed a coculture system derived from previous experiments showing that astrogliosis could be induced in astrocytic cultures. In vivo a mechanical lesion such as a stab wound (Hozumi et al., 1990) or spinal cord compression (Farooque et al., 1995) provokes stereotyped phenotypic changes in astrocytes characterized, in particular, by a hypertrophy of the cell body and processes and an increase in the content of gliofilaments. These gliofilaments are rich in GFAP. GFAP mRNA and GFAP protein levels are increased a few hours and a few days postlesion, respectively (Mucke et al., 1991). Similar changes were obtained in purified astrocytic cultures by Yu et al. (1993), Ghirnikar et al. (1994), and Faber-Elman et al. (1995), who induced astrogliosis by mechanical lesion of the cells. We have taken advantage of the possibility of culturing dissociated neurons on an astroglial monolayer (Noble et al., 1984; Hatten, 1985) to reproduce more completely the phenomena induced by an in vivo lesion, in particular, the presence in the same place of cut ends of both axons and glial processes. The lesions, performed after a few days of coculture, induced phenotypic changes in astrocytes found in the vicinity of the lesion, with hypertrophy of cell bodies and processes. Neither neurite outgrowth nor neuronal migration was observed at the lesion site. This CNS injury model reproduced, therefore, the inability of neurons to regenerate after axotomy into an astroglial scar, something that is classically reported in in vivo experiments (for review, see Reier, 1986). This result is also consistent with those obtained in coculture experiments by Smith et al. (1990), Rudge and Silver (1990), and McKeon et al. (1991), who demonstrated a poor axonal growth of cortical neurons cultured over either mature astrocytes or explant cultures of reactive glia.

This in vitro model does not reproduce, however, all the features of an in vivo injury. The main limitation is that in this model there is no participation of the other cell types present in the CNS, especially microglia, oligodendroglia, and endothelial cells. The impact of microglia-derived factors on the CNS lesion (Giulian et al., 1994) and the inhibitory role of oligodendrocytes on axon growth (Schnell and Schwab, 1990; Lang et al., 1995) have been well documented. A second limitation is that this model does not include the three dimensions of a tissue and thus limits intercellular contacts and excludes, for instance, the possibility for axons to regenerate around a lesion (Foerster, 1982). Altogether, this model must be considered at face value, i.e., as a basis to study specifically the consequences of astrocytic reactivity on axonal growth.

The second methodological basis of our study was the use of antisense GFAP mRNA to alter astrocytic response to injury. Weinstein et al. (1991) and Rutka et al. (1994) have demonstrated a disappearance of astrocytic processes, using a stable transfection of an antisense GFAP construct in astrocytoma cell lines. In an astrocyte primary culture addition of an antisense for GFAP (mRNA, oligonucleotides, or cDNA) prevented the increase in GFAP synthesis and reduced hypertrophy of the cell body observed after a mechanical lesion (Yu et al., 1993; Ghirnikar et al., 1994). We have confirmed these effects of antisense GFAP mRNA in our coculture model in association with a decrease in the capacity of the cells to translate GFAP mRNA.

We have, therefore, used this technique to evaluate the relationship between the morphological differentiation of astrocytes after a lesion and the blockade of axonal regeneration.

\section{Inhibition of hypertrophy induces functional changes in astrocytes beneficial for axonal regrowth}

After antisense GFAP mRNA treatment, neuronal cell bodies and neurites were observed over astrocytes of the lesion border and into the lesion site, in sharp contrast with the paucity of neuronal elements observed in untreated cocultures. Accordingly, the synthesis of the protein GAP-43, which is known to be correlated with nerve sprouting (Schreyer and Skene, 1991), was enhanced, as compared with both unlesioned and lesioned untreated cocultures. These results support our working hypothesis that glial morphological differentiation plays a role in the failure of axonal regeneration at a site of injury. It is at this stage, however, but a matter of speculation as to which mechanisms are altered under these conditions.

A first hypothesis in line with that put forward by several authors (see references and discussion in Reier, 1986; Reier and Houle, 1988) is the possibility that blockade of GFAP synthesispreventing morphological alteration of reactive astrocyteswould have impeded the formation of a physical barrier to axon growth or neuron migration. This cannot be excluded completely. In our experimental conditions, however, this is unlikely, because the axotomized end of the neurites is not, at first, facing hypertrophic astrocytes but, rather, the "empty" zones created by the scratch. In addition, neuronal cell bodies are, at first, present close to the scratch and then disappear. Reactive astrocytes in the 
$3 \mathrm{~h}$ $19 \mathrm{~h}$ L A
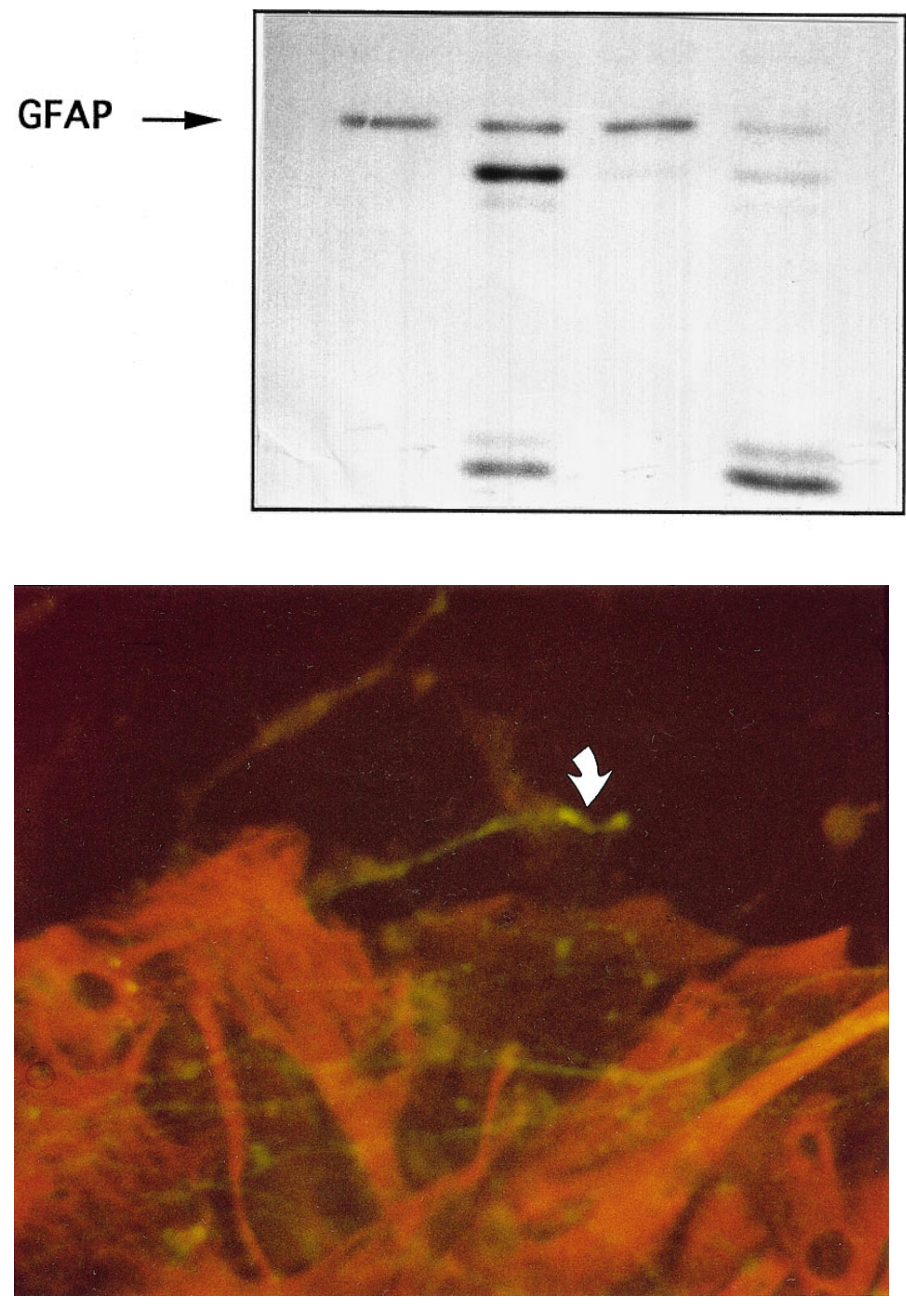

Figure 6. GAP-43 (in green) and GFAP (in red) immunolabeling of injured antisense-treated cocultures. Lesioned cocultures were treated with antisense GFAP mRNA for $48 \mathrm{hr}$. Immunocytochemistry was performed with mouse GAP-43 antiserum (1:10) and rabbit GFAP antiserum (1:50). Arrow points to a GAP-43-labeled growth cone in the lesion border (magnification, $400 \times$ ).

absence of antisense GFAP mRNA seem, therefore, more to offer a poor substratum for axonal growth rather than to act as an actual physical obstacle to it. Several properties of astrocytes reported in the literature are directly relevant to such a hypothesis. It has been shown, in particular, that astrocytes synthesize many components of the extracellular matrix that seem to play major-although opposite-roles in axonal outgrowth. On the one hand, astrocytes synthesize molecules that inhibit axonal growth, such as proteoglycans (Braunewell et al., 1995) or tenascin (McKeon et al., 1991; Faissner and Steindler, 1995). Interestingly, astroglial hypertrophy is associated with an increase in synthesis of both chondroitin sulfate proteoglycans and tenascin (McKeon et al., 1991). Blockade of astrocytic hypertrophy under our experimental conditions, therefore, may block, in parallel, this oversynthesis of potentially inhibitory molecules.

Astrocytes also synthesize laminin (Chiu et al., 1991), which is a well known promoter of axonal growth (Smith et al., 1990).

\section{after transfection}

Figure 5. GFAP immunoprecipitation of in vitro translated RNA of lipofectintreated cocultures $(L)$ or antisensetreated cocultures $(A S)$ at 3 or $19 \mathrm{hr}$. Translated protein was immunoprecipitated with anti-GFAP antibody (Dakopatts, High Wycombe, UK).

Synthesis of this molecule decreases, in parallel to astrocytic maturation, in neuron-astrocyte cocultures (Ard and Bunge, 1988). Again, under our experimental conditions reduction of hypertrophy may be paralleled by a maintained synthesis of the molecule and, therefore, a maintained promotion of axonal regrowth. As regarding laminin, our results also point out two patterns of laminin immunoreactivity similar to those described by Garcia-Abreu et al. (1995), which seem to bear different potentials for axonal growth. Indeed, a punctate pattern of immunoreactivity, apparently located in the cytoplasm of glial cells, was associated with nonpermissive conditions for neurons and axons, whereas a fibrillar pattern, mostly extracellular, was associated with both a dense axonal network and numerous cell bodies. Lesioned cocultures treated with antisense GFAP mRNA exhibited a prominent network of laminin, i.e., a supposedly permissive substrate; in contrast, in untreated cultures, giant astrocytes of the border site, which displayed an apparent intracellular laminin immunolabeling, appeared to be a nonpermissive substrate for neurons. Laminin in its synthesis and its distribution therefore may be one of the factors that play a role in the lack of inhibition of neurite outgrowth after antisense treatment. Alternatively, one cannot exclude that, rather than an alteration-or a lack thereof-in the synthesis of secreted molecules, the maintained ability of reactive astrocytes to support axonal regrowth may be related to membrane-bound molecules involved in cell-to-cell contact between neurons and astrocytes, such as cell adhesion molecules (for review, see Zhang et al., 1995).

In conclusion, blockade of cellular hypertrophy in reactive astrocytes by antisense GFAP mRNA induces a major functional alteration, revealed as modified interactions in cocultured neurons. If, as hypothesized, this functional alteration relates to changes in secreted and/or membrane-bound proteins, it remains to be defined how GFAP synthesis can be linked to these apparently very different phenomena. As a working hypothesis, one may consider changes in the intracellular transport system in which gliofilaments are involved (Steinert and Roop, 1988) or a direct or indirect modulation of genetic transcription, as suggested by Rutka et al. (1994).

\section{REFERENCES}

Andres-Barquin PJ, Fages C, Le Prince G, Rolland B, Tardy M (1994) Thyroid hormones influence the astroglial plasticity: changes in the 
expression of glial fibrillary acidic protein (GFAP) and of its encoding message. Neurochem Res 19:65-69.

Ard MD, Bunge RP (1988) Heparan sulfate proteoglycan and laminin immunoreactivity on cultured astrocytes: relationship to differentiation and neurite growth. J Neurosci 8:2844-2858.

Bottenstein JE (1984) Culture methods for growth of neuronal cell lines in defined media. In: Methods for serum-free culture of neuronal and lymphoïd cells (Barnes D, Sirbasku D, Savo A, eds), pp 3-13. New York: Liss.

Braunewell KH, Martini R, Lebaron R, Kresse H, Faissner A, Schmitz B, Schachner M (1995) Up-regulation of a chondroitin sulphate epitope during regeneration of mouse sciatic nerve. Evidence that the immunoreactive molecules are related to the chondroitin sulphate proteoglycans decorin and versican. Eur J Neurosci 7:792-804.

Chiu AY, Espinosa de los Monteros A, Cole RA, Loera S, De Vellis J (1991) Laminin and s-laminin are produced and released by astrocytes, Schwann cells, and schwannomas in culture. Glia 4:11-24.

Chomczynski P, Sacchi N (1987) Single-step method of RNA isolation by acid guanidium thiocyanate-phenol chloroform extraction. Anal Biochem 162:156-159.

Condorelli DF, Dell'Albani P, Kaczmarek L, Messina L, Spampinato G, Avola R, Messina A, Giuffrida Stella AM (1990) Glial fibrillary acidic protein messenger RNA and glutamine synthetase activity after nervous system injury. J Neurosci Res 26:251-257.

Eng LF (1985) GFAP: the major protein of glial intermediate filaments in differentiated astrocytes. J Neuroimmunol 8:203-214.

Eng LF, Ghirnikar RS (1994) GFAP and astrogliosis. Brain Pathol 4:229-237.

Faber-Elman A, Lavie V, Schwartz I, Shaltiel S, Schwartz M (1995) Vitronectin overrides a negative effect of TNF $\alpha$ on astrocyte migration. FASEB J 9:1605-1613.

Faissner A, Steindler D (1995) Boundaries and inhibitory molecules in developing tissues. Glia 13:233-254.

Farooque M, Badonic T, Olsson Y, Holtz A (1995) Astrocytic reaction after graded spinal cord compression in rats: immunohistochemical studies on glial fibrillary acidic protein and vimentin. J Neurotrauma $12: 41-52$.

Foerster AP (1982) Spontaneous regeneration of cut axons in adult rat brain. J Comp Neurol 210:335-356.

Garcia-Abreu J, Cavalcante LA, Neto VM (1995) Differential patterns of laminin expression in lateral and medial midbrain glia. NeuroReport 6:761-764.

Ghirnikar RS, Yu ACH, Eng LF (1994) Astroglios in culture. III. Effect of recombinant retrovirus expressing antisense glial fibrillary acidic protein RNA. J Neurosci Res 38:376-385.

Giulian D, Li J, Li X, George J, Rutecki PA (1994) The impact of microglia-derived cytokines upon gliosis in the CNS. Dev Neurosci 16:128-136.

Hatten ME (1985) Neuronal regulation of astroglial morphology and proliferation in vitro. J Cell Biol 100:384-396.

Hertz E, Yu ACH, Hertz L, Juurlink BHJ, Schousboe A (1989) Preparation of primary cultures of mouse cortical neurons. In: A dissection and tissue culture manual for the nervous system (Shahar A, DeVellis J, Vernadakis A, Haber B, eds), pp 183-186. New York: Liss.

Hozumi I, Chiu FC, Norton WT (1990) Biochemical and immunocytochemical changes in GFAP after stab wound. Brain Res 524:64-71.

Laemmli UK (1970) Cleavage of structural proteins during the assembly of the head of bacteriophage T4. Nature 227:680-685.

Lang DM, Rubin BP, Schwab ME, Stuermer CAO (1995) CNS myelin and oligodendrocytes of the Xenopus spinal cord-but not optic nerve-are nonpermissive for axon growth. J Neurosci 15:99-109.

Lowry OH, Rosebrough NJ, Farr AL, Randall RJ (1951) Protein measurement with the Folin phenol reagent. J Biol Chem 193:265-275.

Marusich MF, Weston JA (1992) Identification of early neurogenic cells in the neural crest lineage. Dev Biol 149:295-306.

Mc Carthy KD, De Vellis J (1980) Preparation of separate astroglial and oligodendroglial cultures from rat cerebral tissue. J Cell Biol 85:890-902.
McKeon RJ, Schreiber RC, Rudge JS, Silver J (1991) Reduction of neurite outgrowth in a model of glial scarring following CNS injury is correlated with the expression of inhibitory molecules on reactive astrocytes. J Neurosci 11:3398-3411.

McKeon RJ, Höke A, Silver J (1995) Injury-induced proteoglycans inhibit the potential for laminin-mediated axon growth on astrocytic scars. Exp Neurol 136:32-43.

Mucke L, Oldstone MBA, Morris JC, Nerenberg MI (1991) Rapid activation of astrocyte-specific expression of GFAP-lacZ transgene by focal injury. New Biol 3:465-474.

Noble M, Kok-Seang J, Cohen J (1984) Glia are a unique substrate for the in vitro growth of central nervous system neurons. J Neurosci 4:1892-1903.

Reier PJ (1986) Gliosis following CNS injury: the anatomy of astrocytic scars and their influences on axonal elongation. In: Cell biology and pathology of astrocyte, Vol 3 (Fedoroff S, Vernadakis A, eds), pp 263-324. New York: Academic.

Reier PJ, Houle JD (1988) The glial scar: its bearing on axonal elongation and transplantation approaches to CNS repair. In: Advances in neurology: functional recovery in neurological diseases (Waxman SG, ed), pp 87-138. New York: Raven.

Rudge JS, Silver J (1990) Inhibition of neurite outgrowth on astroglial scars in vitro. J Neurosci 10:3594-3603.

Rutka JT, Hubbard SL, Fukuyama K, Matsuzawa K, Dirks PB, Becker LE (1994) Effects of antisense glial fibrillary acidic protein complementary DNA on the growth, invasion, and adhesion of human astrocytoma cells. Cancer Res 54:3267-3272.

Schmechel DE, Rakic P (1979) A Golgi study of radial glial cells in developing monkey telencephalon: morphogenesis and transformation into astrocytes. Anat Embryol (Berl) 156:115-152.

Schnell L, Schwab ME (1990) Axonal regeneration in the rat spinal cord produced by an antibody against myelin-associated neurite growth inhibitors. Nature 343:269-272.

Schreyer DJ, Skene JHP (1991) Fate of GAP-43 in ascending spinal axons of DRG neurons after peripheral nerve injury: delayed accumulation and correlation with regenerative potential. J Neurosci 11:3738-3751.

Silver J, Sidman RL (1980) A mechanism for the guidance and topographic patterning of retinal ganglion cell axons. J Comp Neurol 189:101-111.

Silver J, Edwards MA, Levitt P (1993) Immunocytochemical demonstration of early appearing astroglial structures that form boundaries and pathways along axon tracts in the fetal brain. J Comp Neurol 328:415-436.

Smith DD, Campbell JW (1983) Subcellular location of chicken brain glutamine synthetase. J Biol Chem 258:12265-12268.

Smith GM, Miller RH, Silver J (1986) Changing role of forebrain astrocytes during development, regenerative failure, and induced regeneration upon transplantation. J Comp Neurol 251:22-43.

Smith GM, Rutishauser U, Silver JR, Miller RH (1990) Maturation of astrocytes in vitro alters the extent and molecular basis of neurite outgrowth. Dev Biol 138:377-390.

Steinert PM, Roop DR (1988) Molecular and cellular biology of intermediate filaments. Annu Rev Biochem 57:593-625.

Weinstein DE, Shelanski ML, Liem RKH (1991) Suppression by antisense mRNA demonstrates a requirement for the glial fibrillary acidic protein in the formation of stable astrocytic processes in response to neurons. J Cell Biol 112:1205-1213.

$\mathrm{Yu}$ ACH, Lee YL, Eng LF (1991) Inhibition of GFAP synthesis by antisense RNA in astrocytes. J Neurosci Res 30:72-79.

Yu ACH, Lee YL, Eng LF (1993) Astrogliosis in culture. I. The model and the effect of antisense oligonucleotides on glial fibrillary acidic protein synthesis. J Neurosci Res 34:295-303.

Zhang Y, Campbell G, Anderson PN, Martini R, Schachner M, Lieberman AR (1995) Molecular basis of interactions between regenerating adult rat thalamic axons and Schwann cells in peripheral nerve grafts. I. Neural cell adhesion molecules. J Comp Neurol 361:193-209. 